mansasa

glyndŵn

Glyndŵr University

Glyndŵr University Research Online

Mechanical Engineering

$1-1-2006$

\title{
Simulation of Wind Heat Generator
}

M Katawaluwa

HZhang

Yuriy Vagapov

Glyndwr University, y.vagapov@glyndwr.ac.uk

JEvans

Follow this and additional works at: http://epubs.glyndwr.ac.uk/eng

Part of the Engineering Commons

Copyright $\odot 2006$ IEEE. Reprinted from the proceedings of the IEEE International Conference on Electro/information Technology in East Lansing, MI, USA in May 2006. This material is posted here with permission of the IEEE and the author. Such permission of the IEEE does not in any way imply IEEE endorsement of any of the products or services of Glyndwr University Wrexham. Internal or personal use of this material is permitted. However, permission to reprint/republish this material for advertising or promotional purposes or for creating new collective works for resale or redistribution must be obtained from the IEEE by writing to pubs-permissions@ieee.org. By choosing to view this document, you agree to all provisions of the copyright laws protecting it. The definitive version is available at http://ieeexplore.iee.org

\section{Recommended Citation}

Katawaluwa, M., Zhang,H. Vagapov, Y. \& Evans, J. (2006) 'Simulation of Wind Heat Generator', proceedings of the IEEE International Conference on Electro/information. pp. 479-482, USA, East Lansing,MA.

This Conference Paper is brought to you for free and open access by Glyndŵr University Research Online. It has been accepted for inclusion in Mechanical Engineering by an authorized administrator of Glyndŵr University Research Online. For more information, please contact d.jepson@glyndwr.ac.uk. 


\title{
Simulation of Wind Heat Generator
}

\author{
M. Katawaluwa, H. Zhang, Y. Vagapov, J. Evans \\ North East Wales Institute of Higher Education \\ Plas Coch, Mold Road \\ Wrexham, LL11 2AW, UK
}

\begin{abstract}
Wind turbines are traditionally used to generate electrical energy. However for small, remote applications a wind turbine can also be used to convert wind power into thermal power in order to reduce the cost of energy used for heating systems. The wind heat generator is based on the principle of the Joule machine driven by a wind turbine. To obtain optimal performance the torque-speed characteristics of the turbine and the heat generator should be matched. By recognising this requirement the model of a wind heat generator was developed and simulated. The result of the simulation shows the behavior of the wind heat generator operating at maximum power.
\end{abstract}

\section{INTRODUCTION}

Wind turbines are traditionally used to generate electrical energy rather than thermal energy because electricity is more easily utilised by consumers and converted into other types of energy. However for small, remote applications of wind turbines there is the possibility to use a wind turbine to convert wind power into thermal power directly [3]. The thermal energy produced by a wind turbine can be used to supply a house with heat in order to reduce the cost of gas or other form of energy used in traditional domestic heating systems.

The easiest way to convert mechanical energy into thermal energy is via the Joule machine. A heat generator based on this principle is a mixer installed into a tank with liquid. The shaft of a mixer is rotated by a wind turbine and the liquid is mixed by an impeller. Due to friction among molecules of the mixing liquid, mechanical energy is converted into heat energy. The heated liquid then transfers the heat to a heating system. The process comprising the Joule machine and Savonius wind turbine is shown on the schematic diagram in Fig. 1.

\section{WIND TURBINE}

A wind turbine of the Savonius type for wind heat generation is chosen as an example. This type of turbine is a vertical axis wind turbine. The turbine has a low speed with its tip speed ratio (TSR) not exceeding 1. Savonius wind turbines are usually used for low speed applications such as pumping and very rarely for generating electricity.

Generally the amount of mechanical power generated by a wind turbine depends on wind speed and the parameters of the turbine. It is known [2] that the power delivered by a wind turbine can be expressed as

$$
P=\frac{1}{2} \rho_{A} A C_{P} V^{3}
$$

where $\rho_{A}$ is air density $\left[\mathrm{kg} / \mathrm{m}^{3}\right], A$ is turbine blade area $\left[\mathrm{m}^{2}\right], C_{P}$ is power coefficient, $V$ is wind speed $[\mathrm{m} / \mathrm{s}]$.
The turbine blade area $A$ for a horizontal axis turbine can be found as

$$
A=\pi R^{2}
$$

were $R$ is turbine radius.

For a vertical axis wind turbine the value of $A$ is

$$
A=2 h R
$$

where $h$ is height of turbine rotor.

The torque developed by the wind turbine $T_{T}$ can be calculated as follows.

$$
T_{T}=\frac{P}{\omega}=\frac{\rho_{A} A C_{P} V^{3}}{2 \omega}
$$

The power coefficient $C_{P}$ is a function of TSR.

$$
\begin{aligned}
& C_{P}=f(\lambda) \\
& \lambda=\frac{R \omega}{V}
\end{aligned}
$$

where $\lambda$ is TSR and $\omega$ is turbine angular speed.

The function $C_{P}=f(\lambda)$ is not linear and has maximum $C_{P}^{M A X}$ at $\lambda_{E}$ as it is shown in Fig. 2. To develop the speed torque characteristic of the turbine the speed of wind $V$ should be extracted from (6) and substituted into (4).

$$
\begin{aligned}
& V=\frac{R \omega}{\lambda} \\
& T_{T}=\frac{\rho_{A} A C_{P} R^{3}}{2 \lambda^{3}} \omega^{2}
\end{aligned}
$$

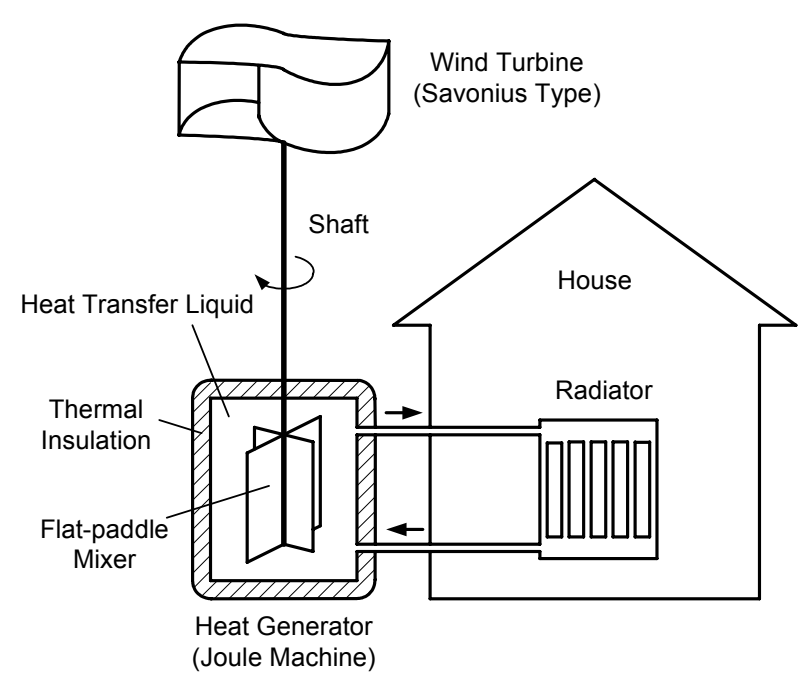

Fig. 1. Schematic diagram of a wind heat generator [3]. 


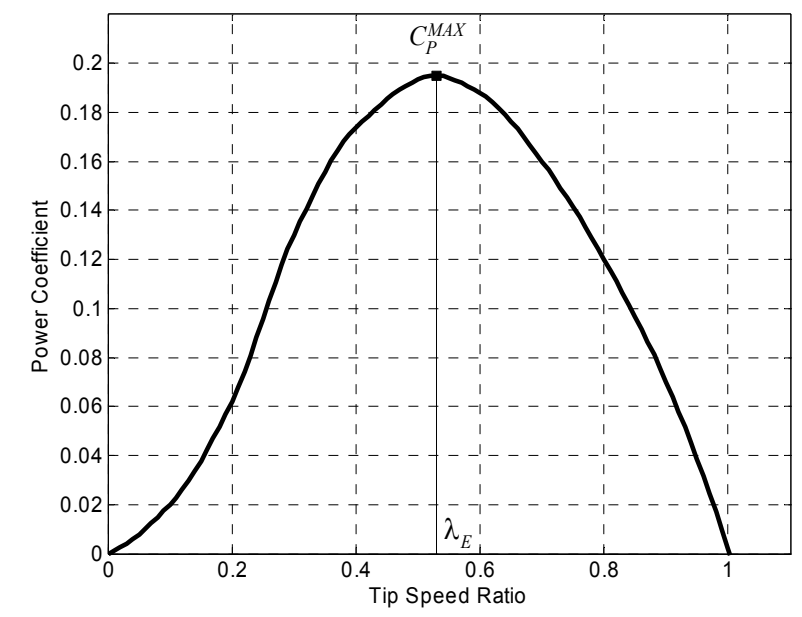

Fig. 2. Power Coefficient $C_{P}$ as a function of TSR $\lambda$ for Savonius wind turbine.

The load torque-speed characteristic of the turbine operating at maximum power can be developed from (8) by substituting the maximum value of the power coefficient $C_{P}^{M A X}$ and the optimal value of TSR $\lambda_{E}$.

$$
T_{G}=\frac{\rho A C_{P}^{M A X} R^{3}}{2 \lambda_{E}^{3}} \omega^{2}
$$

where $T_{G}$ is the load torque of the heat generator.

The load torque-speed characteristic corresponding to (9) is shown in fig. 4 and is the target characteristic for designing the heat generator. In this case the wind turbine delivers the maximum possible amount of mechanical power.

The chosen Savonius wind turbine has $R=0.5 \mathrm{~m}$ and $h=2 \mathrm{~m}$. The power coefficient $C_{P}$ of the turbine with $C_{P}^{M A X}=0.195$ at $\lambda_{E}=0.53$ is shown in Fig. 2 . The family of power-speed characteristics and, correspondingly, the family of torque-speed characteristics of the turbine at different values of wind speed are shown in Fig. 3 and Fig. 4 respectively.

\section{HEAT GENERATOR}

The heat generator based on the principle of the Joule machine is a mixer which converts mechanical power into heat due to friction loss among molecules of the mixing liquid.

The process of mixing with a liquid is described by the following function [1].

$$
N_{P}=f(\operatorname{Re})
$$

where $N_{P}$ is the power number, Re is Reynolds number.

The power number depends on impeller type and Reynolds number. Also the $N_{P}$ can be expressed by

$$
N_{P}=\frac{P g}{\rho_{W} n^{3} d^{3}}
$$

where $P$ is the power supplied by the wind turbine to the mixer, $\rho_{W}$ is the density of the liquid $\left[\mathrm{kg} / \mathrm{m}^{3}\right], d$ is the impeller diameter $[\mathrm{m}], g$ is gravity constant $\left[9.81 \mathrm{~m} / \mathrm{s}^{2}\right], n$ is the speed of the mixer shaft $[\mathrm{rev} / \mathrm{s}]$.

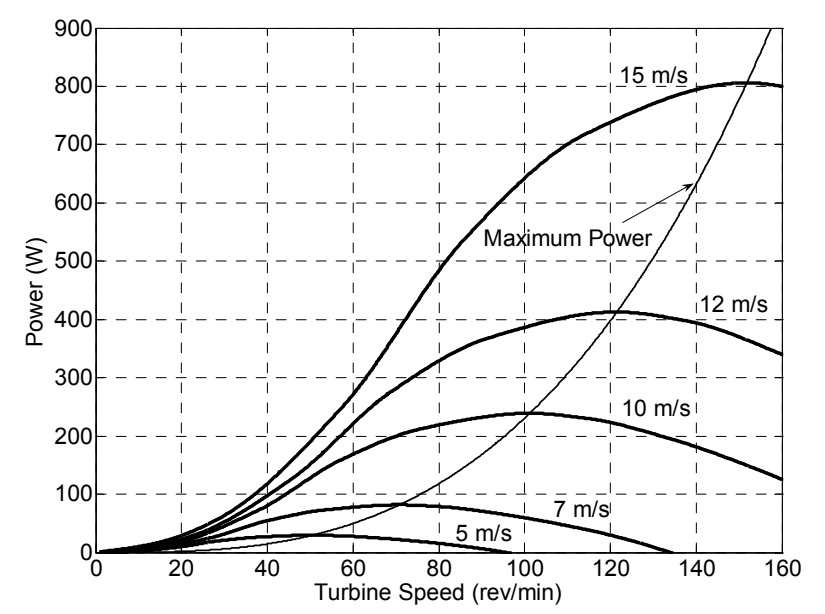

Fig. 3. Family of power-speed characteristics for Savonius turbine shown at different values of wind speed.

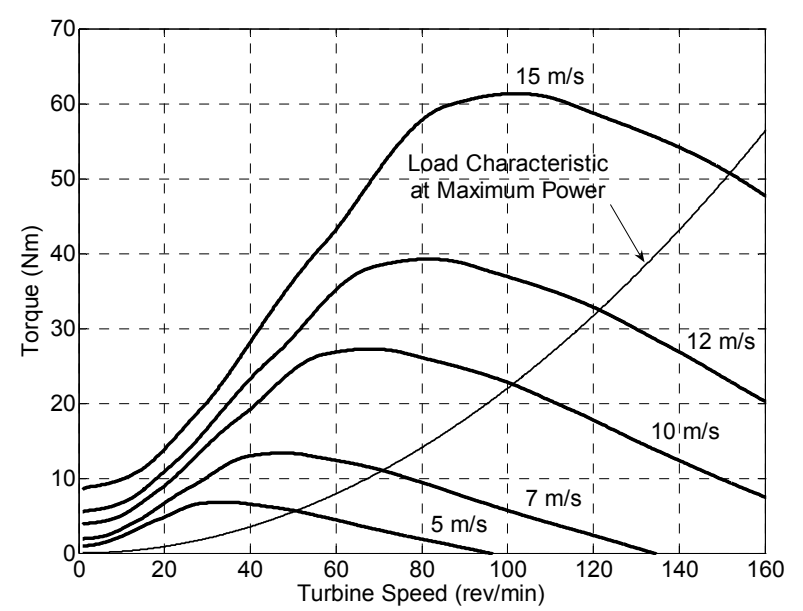

Fig. 4. Family of torque-speed characteristics for Savonius wind turbine shown at different values of wind speed. The arrow points to the torque-speed characteristic of the load required for turbine to operate at maximum power.

The speed of mixer $n$ in rev/s is found as

$$
n=\frac{\omega}{2 \pi}
$$

The power number is also a function of impeller blade width, number of blades and blade angle. For further consideration of the heat generator, a six blade flat-paddle impeller with width/diameter ratio of $1 / 8$ is chosen as an example.

Reynolds number is defined as

$$
\operatorname{Re}=\frac{\rho_{W} n d^{2}}{\mu}
$$

where $\mu$ is viscosity of the liquid $[\mathrm{kg} / \mathrm{m} \cdot \mathrm{s}]$.

The process of mixing with mechanical mixer occurs under laminar or turbulent flow conditions. The condition of the process depends on the value of the Reynolds number. The laminar flow condition takes place at Re below 30 and fully turbulent condition is achieved at Re higher than 10000. The relationship between the power number and Reynolds number, which can be used for both flow conditions, is given by 


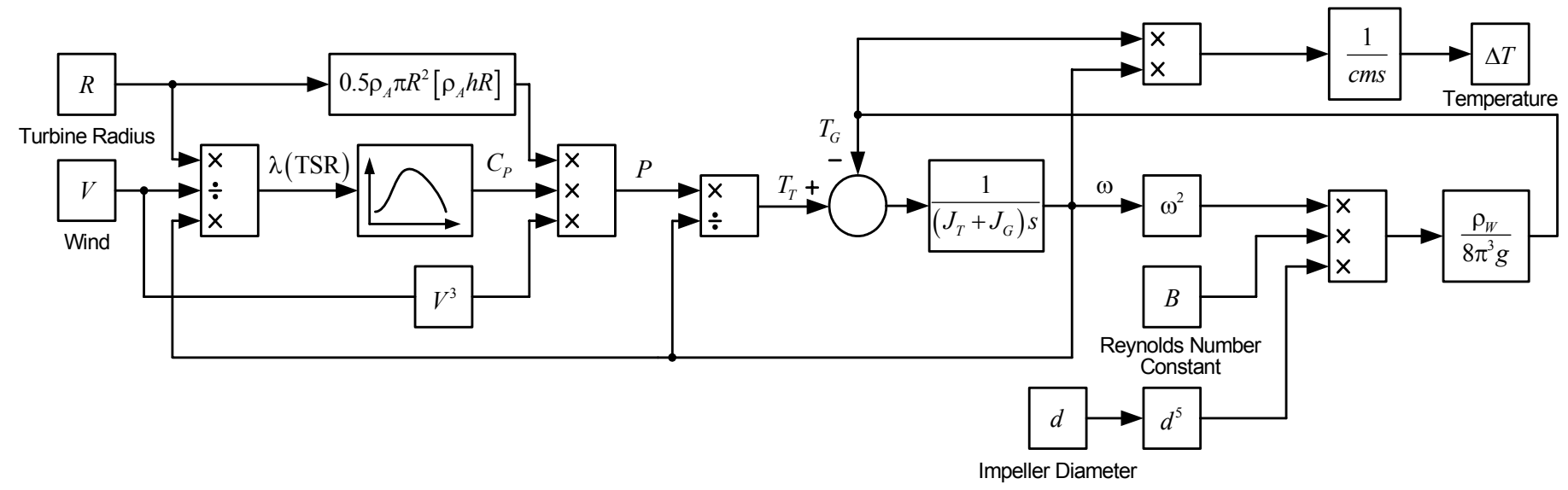

Fig. 5. Block diagram of the wind heat generator for simulation in Matlab/Simulink

$$
N_{P}=B \operatorname{Re}^{z}
$$

where $B$ and $z$ are constants which depend on the value of Re.

Water is chosen as a heat transfer liquid to obtain the turbulent condition and high value of $\mathrm{Re}$ at low rotational speed.

For $\operatorname{Re}<30$ and six blade impeller, the constants $B=110$ and $z=-1[1]$, [4]. Thus,

$$
\frac{P g}{\rho_{W} n^{3} d^{5}}=\frac{B \mu}{\rho_{W} n d^{2}}
$$

In this case the load torque is proportional to the speed and can be expressed as

$$
T_{G}=\frac{B \mu d^{3}}{4 \pi^{2} g} \omega
$$

Reynolds number with values less than 10000 can be achieved only at very low speed of turbine, about $10^{-4} \mathrm{rev} / \mathrm{s}$. This speed is unusual for wind turbines. The actual speed of the turbine is much higher. Therefore (16) cannot be used to develop the load torque-speed characteristic of the heat generator.

For $\operatorname{Re}>10000$ and six blade impeller, the constants $B=5$ and $z=0$ [1], [4]. Thus,

$$
\frac{P g}{\rho_{W} n^{3} d^{5}}=B
$$

This means that the power number does not depend on the Reynolds number. In this case the load torque has the same quadratic form as required in (9).

$$
T_{G}=\frac{B \rho_{W} d^{5}}{8 \pi^{3} g} \omega^{2}
$$

In (18) there is only one parameter which can be changed to adjust (18) to (9) in order to get the required load torque-speed characteristic. This is the diameter of impeller $d$. Substituting (18) in (9) gives the following equality.

$$
\frac{\rho_{A} A C_{P}^{M A X} R^{3}}{2 \lambda_{E}^{3}}=\frac{B \rho_{W} d^{5}}{8 \pi^{3} g}
$$

Therefore the diameter of impeller can be found from

$$
d=\left(\frac{4 \pi^{3} g \rho_{A} A C_{P}^{M A X} R^{3}}{B \rho_{W} \lambda_{E}^{3}}\right)^{0.2}
$$

From (20), for a given type of wind turbine, the diameter of the impeller $d=0.628 \mathrm{~m}$. Using this diameter of impeller, the torque-speed characteristic of the heat generator matches the torque-speed characteristic of the given wind turbine at maximum power.

In order to reduce the diameter of the tank, the mixer can consist of a number of impellers $k$. In this case the diameter of impellers can be calculated using the following formula.

$$
d=\left(\frac{4 \pi^{3} g \rho_{A} A C_{P}^{M A X} R^{3}}{k B \rho_{W} \lambda_{E}^{3}}\right)^{0.2}
$$

During operation of the wind heat generator, mechanical energy converted into heat increases the temperature of the heat transfer liquid in the tank. Under lossless condition, the temperature increase of the liquid $\Delta T$ is proportional to the energy delivered by the wind turbine to the heat generator and can be defined by

$$
\Delta T=\frac{1}{c m} \int P d t
$$

where $c$ is the specific heat of the liquid $\left[\mathrm{J} / \mathrm{kg} \cdot{ }^{\circ} \mathrm{C}\right], m$ is the mass of the liquid in the tank [kg].

The mechanical system "wind turbine - heat generator" is described by the following equation.

$$
\left(J_{T}+J_{G}\right) \frac{d \omega}{d t}=T_{T}-T_{G}
$$

where $J_{T}$ is the wind turbine inertia, $J_{G}$ is the heat generator inertia, $T_{T}$ is the torque developed by the wind turbine, $T_{G}$ is the load torque of the heat generator.

\section{Simulation}

The wind heat generator was simulated using Matlab in accordance with the block diagram shown in Fig. 5. A model of the wind heat generator was based on a set of four equations (8), (18), (22), (23) and the look-up table of the function (5). 


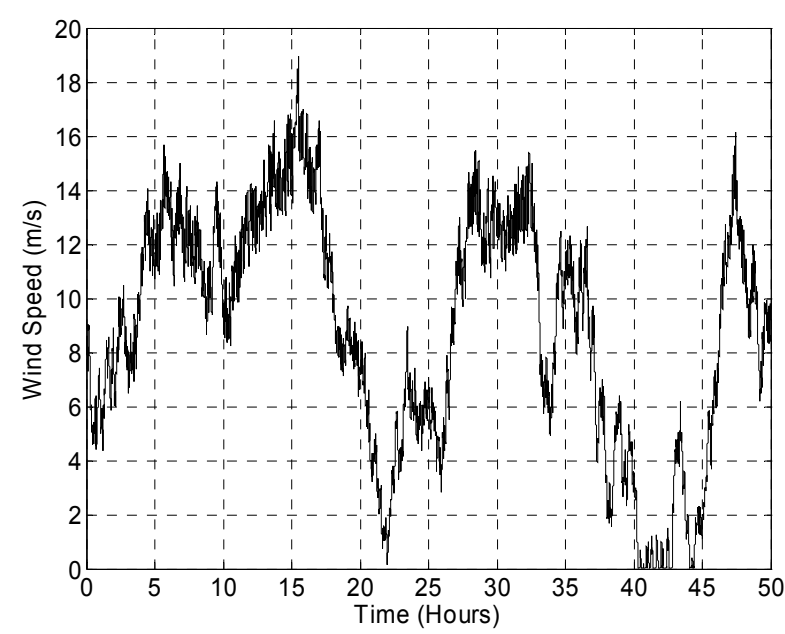

Fig. 6. Wind speed profile for the time duration of 50 hours. The average value of wind speed is $7.5 \mathrm{~m} / \mathrm{s}$.

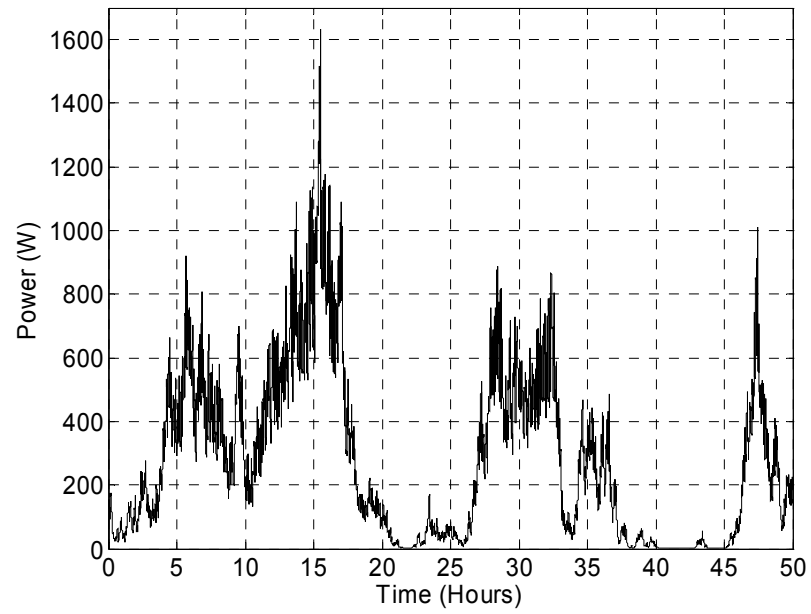

Fig. 7. Power delivered by the wind turbine to the heat generator against time.

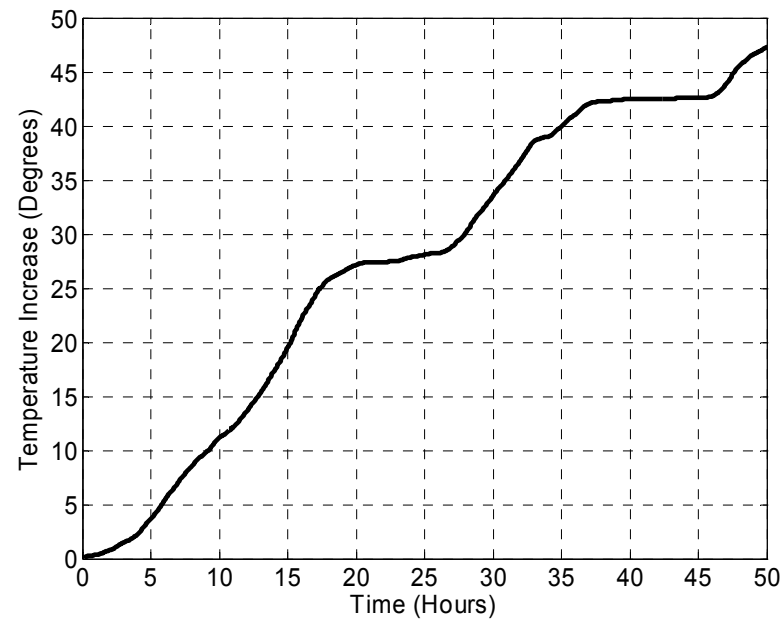

Fig. 8. Temperature increase $(\Delta T)$ of the heat transfer liquid against time.
TABLE I

NOMENCLATURE OF PARAMETERS USED FOR SIMULATION

\begin{tabular}{|l|l|}
\hline Turbine radius, $R$ & $0.5 \mathrm{~m}$ \\
\hline Turbine height, $h$ & $2 \mathrm{~m}$ \\
\hline Maximum of power coefficient, $C_{P}{ }^{M A X}$ & 0.195 \\
\hline Optimum STR, $\lambda_{E}$ & 0.53 \\
\hline Turbine inertia, $J_{T}$ & $1.97 \mathrm{~kg} \cdot \mathrm{m}^{2}$ \\
\hline Air density, $\rho_{A}$ & $1.225 \mathrm{~kg} / \mathrm{m}^{3}$ \\
\hline Water density, $\rho_{W}$ & $1000 \mathrm{~kg} / \mathrm{m}^{3}$ \\
\hline Water specific heat, $c$ & $4180 \mathrm{~J} / \mathrm{kg} \cdot{ }^{\circ} \mathrm{C}$ \\
\hline Reynolds number constant, $B$ & 5 \\
\hline Heat generator inertia, $J_{G}$ & $1.53 \mathrm{~kg} \cdot \mathrm{m}^{2}$ \\
\hline Impeller diameter, $d$ & $0.628 \mathrm{~m}$ \\
\hline Mass of liquid in the tank, $m$ & $200 \mathrm{~kg}$ \\
\hline
\end{tabular}

The nomenclature of parameters used for simulation is given in Table I. It is important to note that some of these parameters are using example values.

An example of wind speed profile, shown in Fig. 6, gives the fluctuation of the wind speed over a duration of 50 hours. The wind profile has significant turbulence and value of average speed $(7.5 \mathrm{~m} / \mathrm{s})$. It is used in order to simulate the performance of the wind heat generator at low and high wind speeds. The results of simulation under lossless condition are given in Fig. 7 and Fig. 8.

An electrical generator used with a wind turbine to produce electricity usually has a limited power output. When a gust occurs, a wind turbine delivers a peak of mechanical power. If the peak is higher than the rated power of the electrical generator, the generator cannot convert an exceeded mechanical power into electrical power. Compared to an electrical generator, the heat generator converts all the power delivered by a wind turbine into heat, increasing the temperature of the heat transfer liquid. Fig. 8 shows the temperature increase of the liquid in the tank. It can be seen that the higher peak of power, the faster the temperature rising.

\section{CONCLUSION}

The model proposed in this paper can be used for basic investigation of the wind heat generator. In order to operate at maximum power, the match between the torque-speed characteristics of the wind turbine and the heat generator should be provided. The match can be achieved by calculation of the diameter of impeller, a general criterion for design of the heat generator.

However, the process of mixing considered in the paper is based on an assumption that the main volume of the heat transfer liquid is not mobile. To prevent mobility of the main volume of the liquid, the tank should be provided with wall baffles.

\section{REFERENCES}

[1] R. R. Hemrajani and G. B. Tatterson, "Mechanically stirred vessels", in Handbook of industrial mixing: science and practice, E. L. Paul, V. A. Atiemo-Obeng and S. M. Kresta, Ed., New Jersey: Wiley, 2004, pp. 345390.

[2] E. W. Golding, The generation of electricity by wind power, London: Wiley, 1977.

[3] N. Gulia and A. Nikonov, "Money from air", Ogonyok, vol. 23, pp. 2328, June 2001.

[4] A. G. Kasatkin, Chemical technology processes and apparatus, 7th ed, Moscow: Goskhimizdat, 1961. 